\title{
LEXICAL SEARCH AND ORDER OF MENTION IN SENTENCE PRODUCTION
}

\author{
Wörter müssen nur aktualisiert, \\ Sätze müssen erzeugt werden. \\ Manfred Bierwisch (1979, p. 38)
}

\section{INTRODUCTION}

In the process of speaking conceptual content is expressed in linguistic form. This requires the speaker to make a variety of conceptual as well as linguistic decisions, and it is still a mystery how these decisions interact in the generation of fluent speech. Among the conceptual decisions taken are ones of content selection and linear order. Content selection is a matter of deciding what should be expressed, given the speaker's intentions and given mutual knowledge in the speaker-listener context. It will involve retrieval of information from memory or from the on-going scene in which the speaker is present. However, at the same time it is largely impossible for a speaker to give simultaneous expression to two or more units of information (let us call them "thoughts"). For linguistic expression these need be strictly ordered. The ordering of this information for expression we will call "linearization". Some major determinants of linearization are, once again, mutual knowledge but also "economy" for working memory: speakers appear to order thoughts for expression such that load on working memory during speaking is minimized (cf. Levelt, 1979 a, b , 1981). These are essentially non-linguistic determinants, however, and one may ask whether linguistic factors also exert an influence on ordering in expression. Among the linguistic decisions to be taken by the speaker are those Garrett (1975) calls "functional" and "positional" decisions. Functional decisions involve, in particular, lexical choice: words are selected for the expression of thoughts by a process of lexical search. Kempen and Hoenkamp (1979) and Kempen and Huybers (1980) argue convincingly that this search is, in the first instance, a search for "lemmas" which are still unspecified for phonetic or articulatory form. Positional decisions, on the other hand, have to do with the realization of appropriate syntactic frames and grammatical formatives. Do lexical and syntactic decisions affect the process of linearization, or should linearization be understood as a relatively 
autonomous conceptual process, one which feeds forward onto linguistic decision making but does not receive feedback from that level? Or, in other words: are linearization and linguistic formulation embedded in a heterarchical organization, where every component can "talk" to the other, or is speaking rather a more hierarchical process in which not all components can directly interact? A theory of the latter kind is stronger than one of the former, and should receive our favor.

Earlier work on linearization (Levelt, 1979 a, b, 1981) has not shown any feedback from the linguistic to the conceptual level in speaking. However, this was not especially the aim of that research. Rather, it was investigated how thoughts would be expressed from sentence to sentence in discourse. In order to give the idea of feedback from the linguistic level a fair test, experiments are needed in which lexical search and syntactic "framing" might affect information ordering decisions.

Let us make this more concrete by considering an example. An observer is asked to describe the events he will see and is shown a circle and a triangle on a screen. The circle is to the left of the triangle. At a certain moment, the circle moves upward a bit, and somewhat later the triangle makes a similar vertical movement. If the interval between these two events is large, the observer will probably say something like: "The circle is rising ... The triangle is rising". At shorter intervals, one may expect sentence coordination: "The circle is rising and the triangle is rising", and at still shorter intervals NP-coordination may result: "The circle and triangle are rising". If such variations in formulation in fact result one could partly account for them in terms of the ordering of percepts: it is natural and appropriate to express the order of events by a corresponding order of phrases. Moreover, if the two events are perceived as parts of a single simultaneous event (when the time interval between them is null), NP-coordination would be especially appropriate to express this. In short, and hardly surprisingly, conceptual factors affect linguistic choice. Event order is a major determinant of conceptual coding, which in turn governs linguistic order. The issue we want to address in this paper is whether order of mention can also be affected by non-conceptual linguistic decisions, i.e. by functional and positional operations. In the present context, this would mean that order of mention of two events is affected by factors such as syntactic framing and lexical search.

Let us first consider possible effects of positional decisions. A simple example can help clarify this. Suppose we give the observer the instructions to describe what he sees using a fixed syntactic frame: "X rose before $\mathrm{Y}$ rose". If the circle goes up first, that event has to be mentioned in first position. 
If, however, the fixed frame is "Before $\mathrm{X}$ rose, $\mathrm{Y}$ rose", the circle's rising has to be mentioned in second position. Choice of syntactic frame thus affects order of mention. One might argue that this is a trivial case because in normal speech such frames are not given beforehand, but selected by the speaker to give appropriate expression to relevant content. Though this may be the rule, there are well-documented exceptions. Bühler (1908) describes how the subjects in his experiments chose a syntactic frame before filling in the contentwords: "When we want to express a difficult thought, we first select the syntactic form for it, we first become conscious of the operational plan, and it is this plan which then controls the wording" (p. 86). And in 1934 he writes that "an empty syntactic schema preceded the actual formulation of an answer" (p. 253). If " $X$ before $Y$ " or "Before $X, Y$ " are examples of such syntactic schema's, they may well determine the order of mention of events. Kempen (1977) gives examples of everyday situations in which syntactic frames clearly have priority in expression. In the repetitive speech of a radio sports reporter, for instance, the on-going events are cast in pre-established syntactic frames. Levelt and Kelter (1981) show that the syntactic form of a question can affect the frame of the answer, without any "conceptual intervention".

So, it would be wrong, a-priori, to reject the hypothesis that positional decisions may affect order of mention in everyday speech. This issue, we think, is an open one, and deserves careful experimentation.

The present study, however, is limited to the possible influence of functional linguistic decisions on order of mention. More specifically, it addresses the question whether lexical search affects this order. Let us consider again the circle-and-triangle situation. If the two figures move upwards simultaneously, perceived order of events can no longer be a determinant of order of mention. Still, in this case there may be other conceptual or perceptual influences on this. The leftmost figure, for instance, may be mentioned first (this was in fact the subjects' dominant tendency in our preliminary experiments). But if the objects' positions in the array are controlled for as well, will difficulty of lexical search demonstrably affect order of mention? If it is made difficult for a subject to find the name for the triangular object he perceives, will he tend to mention its rising in second position? Or is the decision about order of mention taken at another - earlier - level at which difficulty in naming plays no role? In that case difficulty in lexicalizing may affect speech latency if the difficult word is early in the sentence, but should not affect its position in the sentence. 


\section{EXPERIMENT 1. USING ALLONYMS}

Let us start with the question how one might influence the ease of actualizing words during sentence production. Our first effort in this direction was as simple as it was artifical: We asked subjects to give event descriptions of the sort mentioned above. But instead of always calling a triangle "triangle", a subject was required to use a new name for it periodically during the experiment: for one block of trials it was to be called "tent", then "roof" for the next block, etc. Using such allonyms might make it more difficult for a subject to name this figure, and we wanted to learn if this would affect order of mention, provided the name of the other figure (e.g. "circle") was kept the same. Lindsley (1976) showed that using allonyms increased speech latencies in a task where subjects had to describe static pictures of events.

We were also interested here in possible effects of distance in a sentence between the two names, and of their positions in the sentence. The possible role of distance - grammatical as well as measured by separation in words - is best illustrated by means of examples of NP-coordination versus sentence coordination.

(1) Circle and triangle go up

(2) Circle goes up and triangle goes up

The two figure names in sentence (1) fall within a single NP and are closer than in sentence (2), where they occupy different clauses. An effect of naming difficulty on order of mention seems more likely in the former than in the latter case, since the search for the two names, as parts of the same phrase and in close succession, will almost surely overlap in time. The one found first thus has a good chance of appearing in first position. In the case of sentence coordination, on the other hand, a subject might begin to utter the first clause before having initiated retrieval of the second figure name here; there would be less occasion for a "race" between the two lexical search processes.

A further issue is that in both NP- and S-coordination constructions discussed so far, circle and triangle are "on a par": with equivalent simultaneous motion, the informational force of a sentence is hardly affected if the figure names change place. This is quite different if a sentence such as (3) is used

(3) Circle, which is next to triangle, goes up.

If a speaker uses this sentence, he is describing just one of the two events, 
using the other figure and event as a reference point. If the speaker is free to choose which event he will focus on, we can ask whether his decision will depend on naming ease. If indeed the event involving the easy name is chosen, one would have some evidence for feedback from lexical search to conceptual focussing (which, in its turn, determines order of mention in the sentence), i.e. to a very early stage in speech planning.

Finally, we were interested in possible effects of naming difficulty on latency to begin speaking. Sentences (1) to (3) begin with a figure name. One might expect that a difficult name would increase speaking latency if it appears in sentence-initial position. But what if the first name to be mentioned only comes somewhat later on in the sentence? To get an impression, we used a fourth sentence type, otherwise analogous to sentence (3):

(4) Up goes circle, which is next to triangle

Here the direction of movement is topicalized, which has the effect of moving the figure name away from initial position. Since this sentence starts with the movement predication, one can ask whether the formulation of the sentence is complicated by lexical difficulty, or whether such an effect is limited to sentence-initial constituents. The latter finding would suggest that a subject can start speaking before any figure name has been found by lexical search.

In summary, we designed an experiment in which subjects had to describe two simultaneously moving figures by means of a fixed syntactic frame. These frames were Dutch equivalents of the forms (1)-(4). To vary naming difficulty, we instructed a subject to use an allonym, e.g., "roof" for triangle, and changed the allonym to be used from one set of trials to the next. As dependent variables, we took the order of mention of the two figures in the given fixed syntactic construction, and latency to begin saying the sentence after stimulus onset.

\section{Method}

The experiment was run under the control of a PDP 11/55 computer. The graphics used were presented on an electronic display (Vector General) interfaced to the computer. They consisted of three geometric figures, some of which moved in upward or downward direction. The time course for one trial was as follows. First, a small cross appeared in the middle of the screen which served as a warning signal and fixation point. After one second, three figures appeared, positioned in triangular form around the cross (see Figure 1). 


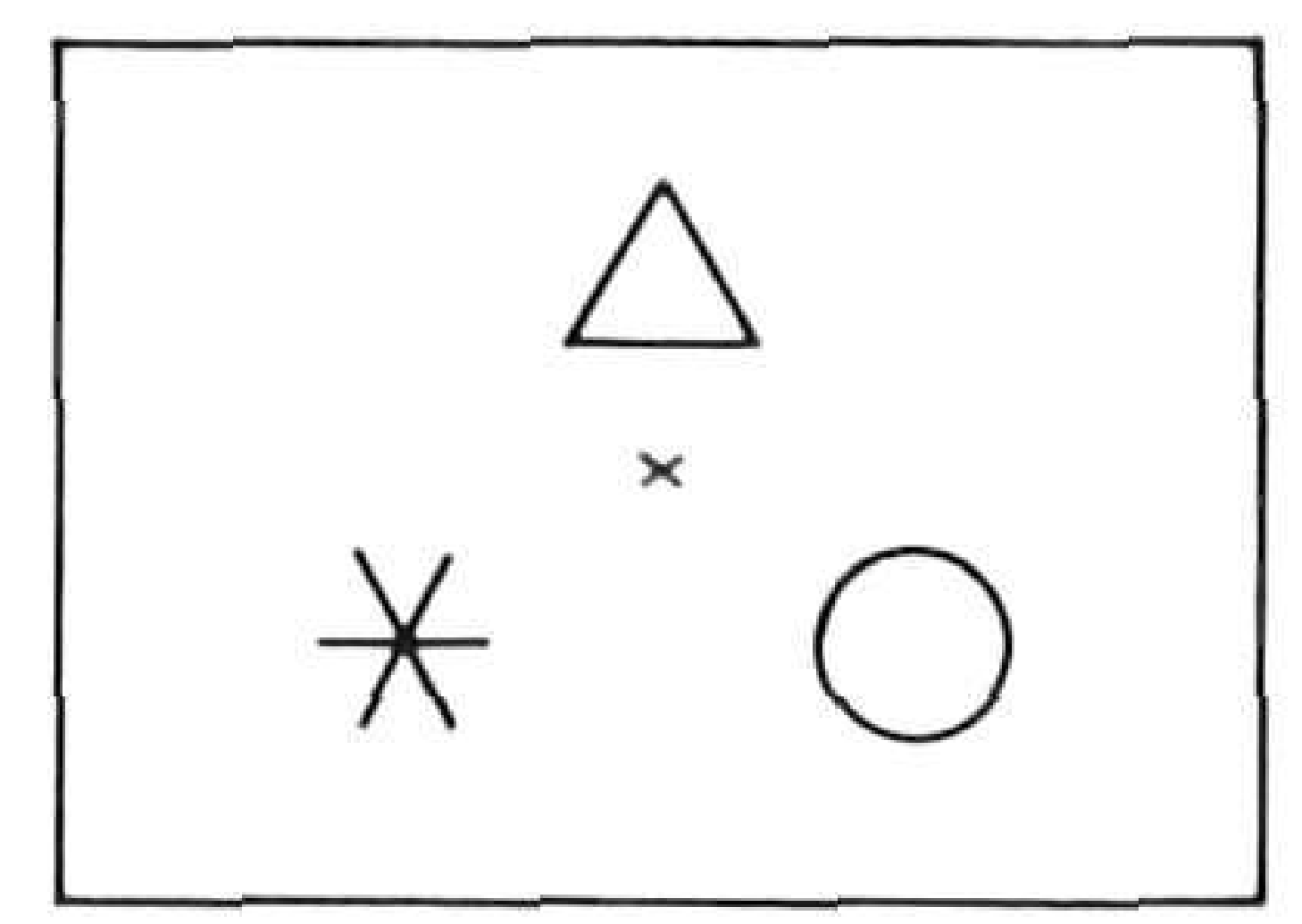

Fig. 1. A stimulus picture of Experiment 1; in Experiments 2 and 3 similar pictures were presented (only figures differed).

Immediately following this appearance, one or two of the figures began a phi-movement. A vertical displacement was carried out in three steps with between-step intervals of $60 \mathrm{~ms}$, amounting to a shift of $2 \mathrm{~cm}$ (2 degrees of visual angle). Following this event, the figures remained in their final positions for $820 \mathrm{~ms}$. The picture then disappeared. So the total event, including warning signal, had a duration of exactly two seconds. Response latency was defined as the time between appearance of the picture and onset of the utterance. By pressing a push-button, the subject could initiate the following trial.

The experiment was divided into blocks of trials so we could instruct subjects to change syntactic frames and allonyms used. Each block consisted of 36 trials, preceded by 3 practice trials. On 24 trials two of the figures moved - simultaneous and in the same direction, both upward or both downward - so that all four syntactic frames (see below) were appropriate. One of the moving figures was always chosen out of the set cross, star and diamond which were described with their normal names in Dutch, namely "kruis", "ster" and "ruit", respectively. The other moving figure was chosen equally often from one of two pairs: square and circle or pentagon and triangle. In each block, the figures of one pair were named with allonyms and those of the other pair with their normal, geometric names. Half of the descriptions contained two normal names, and the other half one normal name and one allonym. The normal Dutch name for square is "vierkant", the allonyms used were "doos" (box) and "blok" (block); for circle the normal name is "cirkel" and the allonyms used were "munt" (coin) and "schijf" (disk); pentagon is normally called "vijfhoek", while the allonyms were "mijter" (mitre) and "vlieger" (kite); for triangle the normal name is "driehoek", the allonyms used "tent" (tent) and "dak" (roof). The positions of the two moving figures were completely counterbalanced. Apart from 24 experimental trials each 
block also contained 12 distraction trials. Of these there were 3 trials where no figure moved and where the subject should remain quiet, and 9 in which only one figure moved, chosen equally often from the three groups. The order of trials within a block was randomized.

The four syntactic frames we required subjects to use for the events where two figures, $x$ and $y$, moved were the following four:

(1) NPC: noun phrase conjunction

" $x$ en $y$ gaan omhoog/omlaag"

( $x$ and $y$ go up/down)

(2) SC: sentence conjunction

" $x$ gaat omhoog/omlaag en $y$ gaat omhoog/omlaag"

( $x$ goes up/down and $y$ goes up/down)

(3) SS: subject first, subordinate clause

" $x$, die naast/boven/onder $y$ staat, gaat omhoog/omlaag"

( $x$, that next to/above/below $y$ is, goes up/down)

(4) VS: verb first, subordinate clause

"omhoog/omlaag gaat $x$, die naast/boven/onder $y$ staat"

(up/down goes $x$, that next to/above/below $y$ is)

The syntactic frame for the description of a single moving figure was " $x$ gaat omhoog/omlaag" ( $x$ goes up/down) throughout the experiment. Each subject received one block for each of the four syntactic frames; the order of the syntactic frames was varied over subjects according to a Latin Square design. The use of allonyms also changed per block. Half of the subjects first had to use "doos" and "munt", then "vlieger" and "dak", then "mijter" and "tent" and finally "blok" and "schijf". For the other half of the subjects the order was: "mijter" and "tent", "blok" and "schijf", "doos" and "munt", and finally "vlieger" and "dak".

Apart from three practice trials at the beginning of each block, there was also one practice block at the beginning of the experiment. Though the form of descriptions was left free in this block, most of the times syntactic frames (1) and (2) were chosen.

\section{Procedure}

The subject was seated in a sound proof booth $50 \mathrm{~cm}$ from the stimulus display. He or she was instructed to give the verbal description for an item as soon as possible after seeing figures move. Latency to speech was measured 
by a voice-operated relay and real-time clock interfaced to the computer. All test sessions were also tape-recorded.

The experimenter monitored what the subject said and viewed the correct description and latency recorded typed out on a teletype. With this information at hand, he could decide if the utterance produced was correct and the measurement for the latency reasonable, e.g. not a result of other noise than speech on part of the subject. When an error occurred, the experimenter pressed an error-button with the effect of presenting the picture again at the end of the current block. If the description given and the latency measured were both unproblematic, the experimenter pressed one of two buttons, indicating which of the two moving figures was mentioned first in the utterance. Codes for the figures and latencies recorded were stored in the computer for later analysis.

Twenty-one high school and university students living in Nijmegen participated in the experiment. Each subject received 7 guilders for the 45 minutes needed for the experiment.

\section{Results}

For each subject, we calculated mean latency, mean variance of latencies - not including the variance between conditions - and percentages of error made, not including "technical" errors. The means and standard deviations of these three measures over subjects were also calculated. Data from subjects who had a value in one of the three distributions that was more than two standard deviations from the overall mean were discarded and new means and standard deviations were calculated. This was repeated iteratively until no subjects with such extreme values remained. In this way data from five subjects were excluded from further analysis. These five each had extremely high (as defined above) error rates, namely at least $24 \%$, vis-à-vis $12 \%$ for the remaining subjects. The variance of 3 of the 5 subjects and the mean of one of these 3 also exceeded the means of the remaining subjects for at least 2 standard deviations. For those five subjects the mean latency was $250 \mathrm{~ms}$ above the mean of the remaining 16 .

The central question in the experiment was whether naming difficulty would influence the order of mention. This does appear to have been the case: of the utterances containing an allonym, 70.5\% had that allonym in first position. So, contrary to our expectations, there was a tendency to start with what we considered the difficult name; this was a highly significant result 
$(t=6.994, \mathrm{df}=15, \mathrm{p}<.001)$. Furthermore, this tendency was independent of the syntactic frame of the utterance.

An analysis of variance was performed on the (arcsine-transformed) proportions of utterances containing an allonym, that had the normal or easy name (E) in first position and the allonym or difficult name (D) in second position (the ED-utterances). Independent variables were Subjects, Syntactic Frames and Figure-Pairs (the actual pairs of figures that were presented); Subjects and Figure-Pairs were taken to be random factors. The factor Figure-Pairs is highly significant $\left(\mathrm{F}_{11,165}=6.794, \mathrm{p}<.001\right)$. When square and circle had to be named with allonyms, they occurred in first position more often than is the case with pentagon and triangle ( $76 \%$ vs $65 \%)$. Subjects also varied among themselves in positioning the allonym first $\left(\mathrm{F}_{15,165}=2.464, \mathrm{p}<.01\right)$, but no subject used it less often than the normal name in first position. Syntactic frames, our main control variable, was not significant at all. The percentages of utterances with allonym in first position were $72.3 \%$ for frame NPC, $71.4 \%$ for SC, for SS $68.0 \%$ and for VS $70.4 \%$.

Our second dependent variable was speech onset latency. In Figure 2 are plotted the mean latencies of utterances with two normal, easy names (EE: easy easy), the means of the utterances with a normal name in first and an allonym in second position (ED: easy difficult) and the means of those utterances with an allonym first and a normal name second (DE: difficult easy). The total mean latencies (e) as well as the means for each of the four syntactic frames separately $(\mathrm{a}-\mathrm{d})$ are plotted.

When an utterance contains an allonym, then starting with that allonym gives a shorter latency than starting with the other, normal figure name. In a least squares analysis of variance with the factors Subjects, Syntactic Frames and Order of Mention (ED vs. DE, now introduced as independent variable), performed on the latencies of the utterances containing an allonym, this difference is significant $\left(\mathrm{F}_{1,15}=8.485, \mathrm{p}=.01\right)$. Also significant was the difference between Syntactic Frames $\left(\mathrm{F}_{3,45}=14.457, \mathrm{p}<.001\right)$. Although the interaction between Syntactic Frames and Order of Mention is not significant $\left(\mathrm{F}_{3,45}=1.062, \mathrm{p}>.25\right)$, there is nevertheless an effect of Syntactic Frame on the latency-difference between ED and DE utterances. Separate t-tests for comparing ED and DE give a significant result only for those syntactic frames in which the naming variation occurs in the first word of the utterance: for frame NPC $(\mathrm{t}=3.045$, $\mathrm{df}=45, \mathrm{p}<.01)$, for $\mathrm{SC}(\mathrm{t}=2.112, \mathrm{df}=45, \mathrm{p}<.025)$ and for SS $(\mathrm{t}=1.783$, df $=45, \mathrm{p}<.05)$. For frame VS where the name occurs later in the utterance, $t=-.137, \mathrm{df}=45$, $\mathrm{p}>.25$. 
(a)

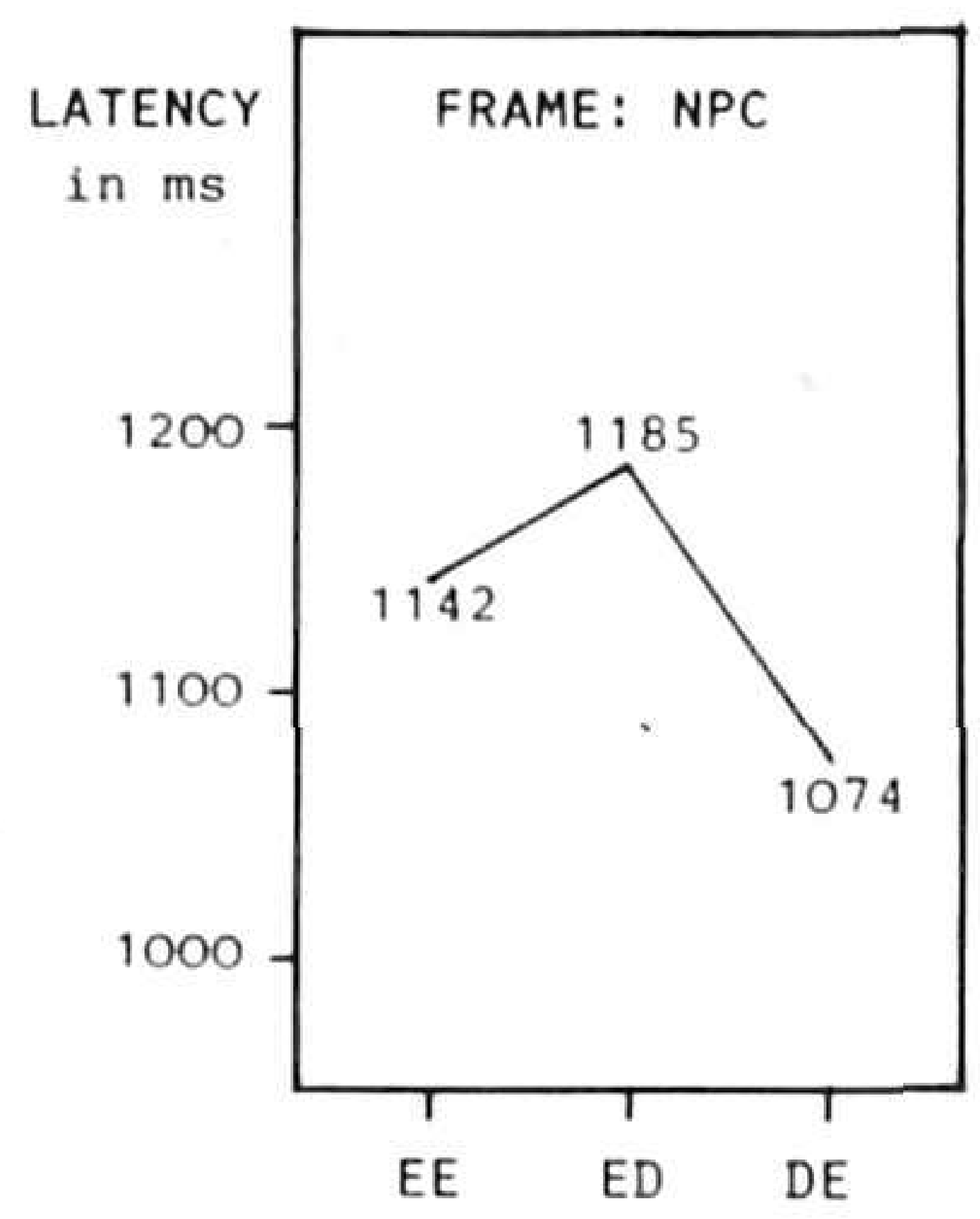

(d)

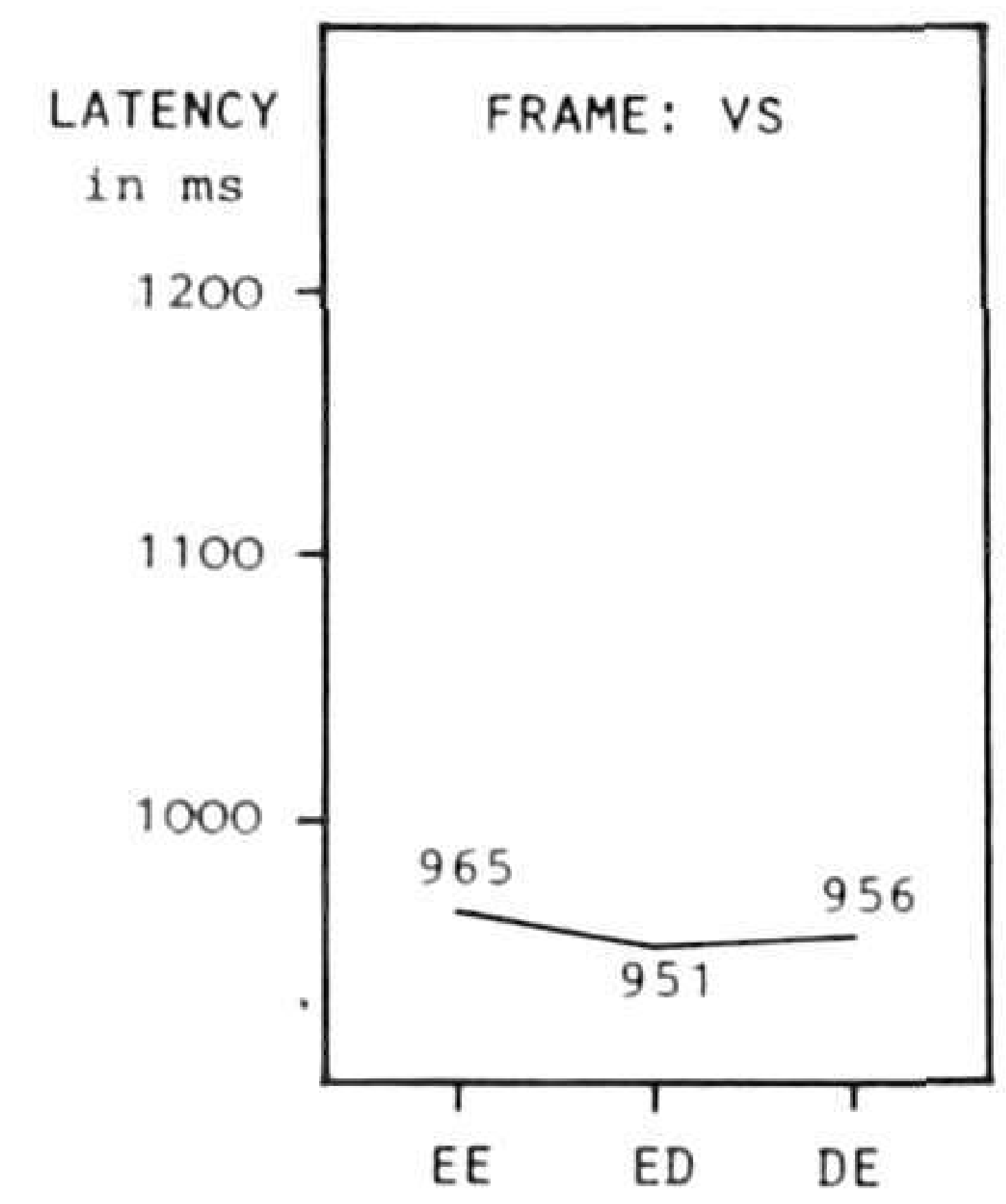

(b)

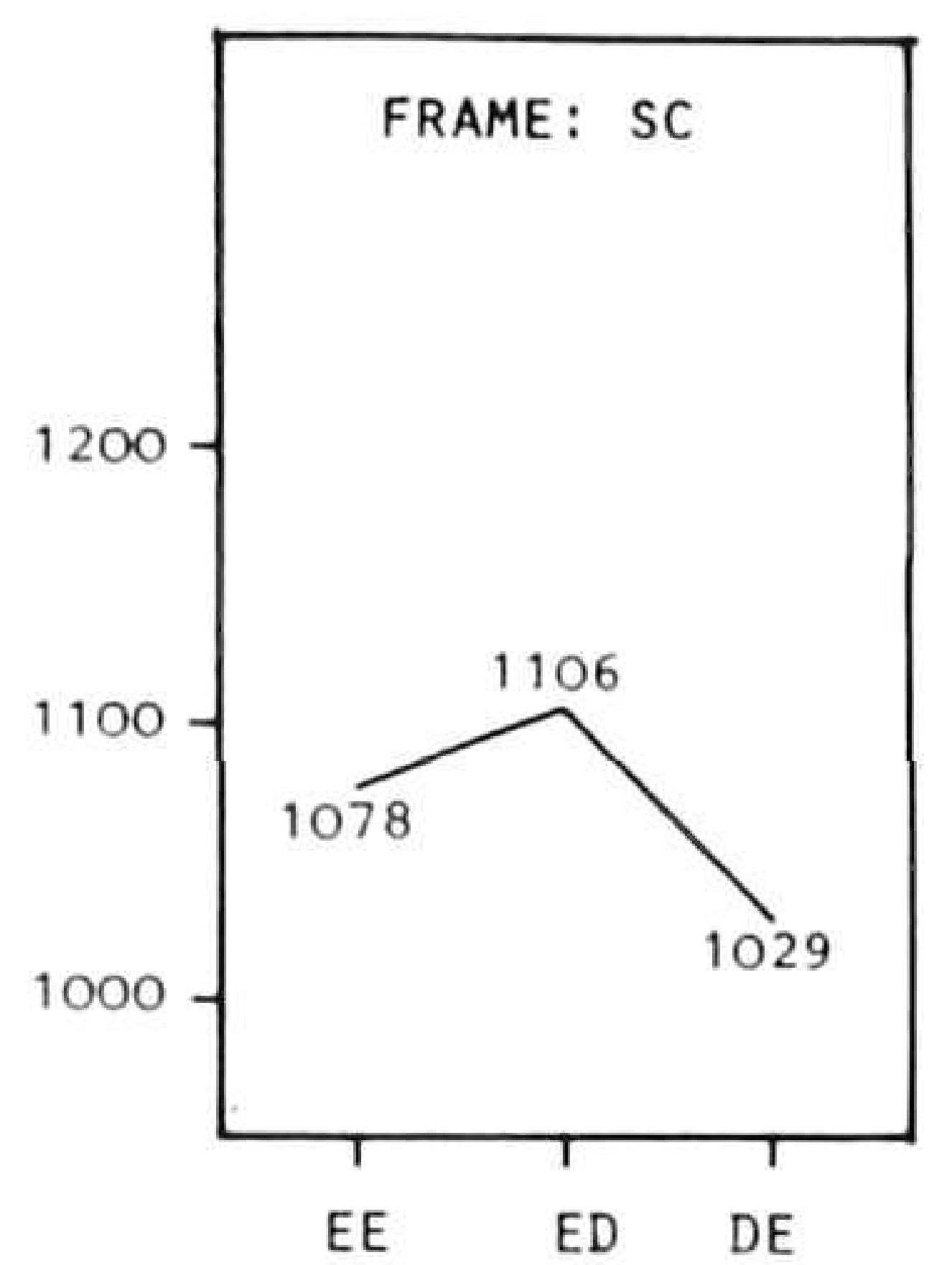

(c)

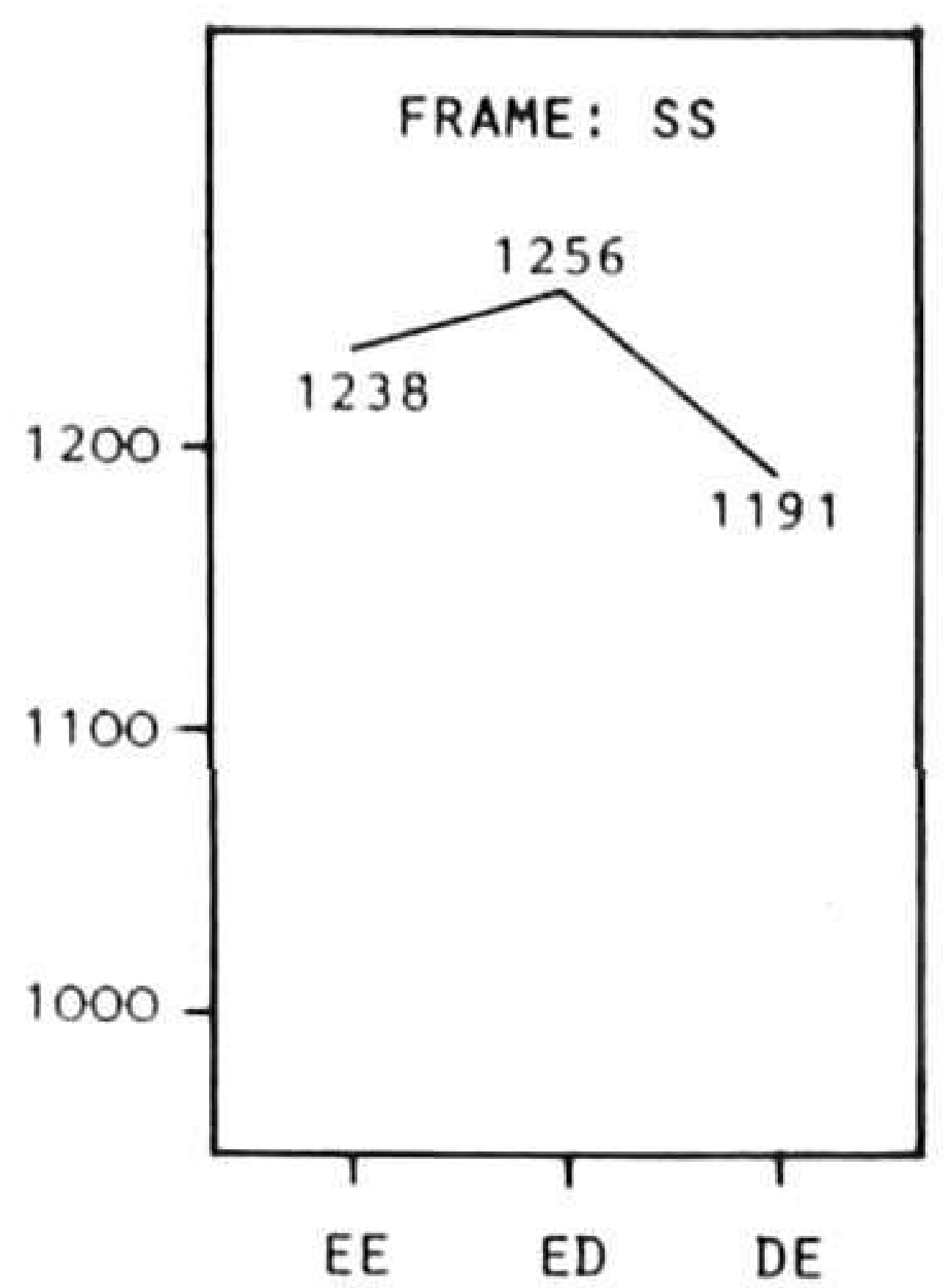

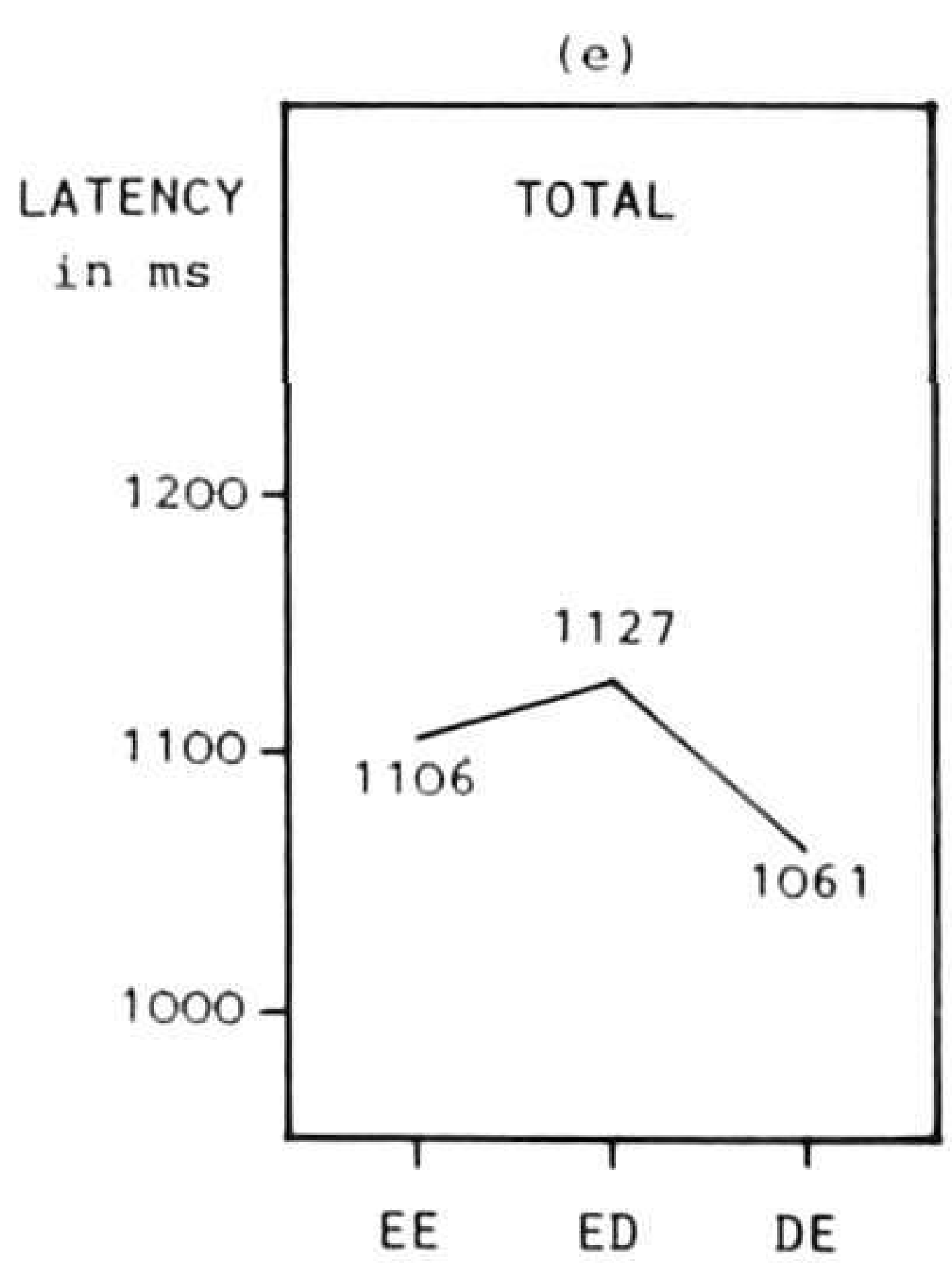

Fig. 2. Mean latencies of utterances with two normal ("easy") names (EE), normal name in first and allonym ("difficult" name) in second position (ED) and allonym in first and normal name in second position (DE). In (a) this is plotted for syntactic frame NPC, in (b) for frame SC, in (c) for SS and in (d) for VS; (e) gives the total means.

\section{Discussion of the results}

The main finding of this experiment is that use of allonyms did affect order of mention, but in a way opposite to our expectations; in $70.5 \%$ of the cases the allonym was mentioned in first position. There is no indication that using the allonym was more difficult for the subject. On the contrary, there is reason to believe that it was easier: from Figure 2 it appears that when the allonym is in first position, the latency to speech is shorter. This effect is 
absent only (this time in line with our expectations) for the fourth syntactic frame, where the first figure name mentioned does not come in sentence initial position. The shorter speech latencies for the other three frames with the allonym in sentence-initial position are just the reverse of Lindsley's (1976) findings, who found an increase of speech latency in such cases. How could it be that allonyms are relatively easy in our case? Presumably, the subject develops a special strategy to cope with the experiment's requirements. The strategy could be this: (1) keep the trouble figure (i.e., the figure with the assigned allonym) in the perceptual focus of attention (2) at each trial keep the allonym available in short term memory (3) use a focus- first order of mention. This procedure would be both approriate and effort reducing. It is appropriate in that an event which is emphasized by the experimental instructions receives priority of mention; it is effort-reducing in that STM is relieved at the earliest possible moment, from the beginning of the sentence. Retrieval from STM is moreover rapid, so that the speech latency can be quite short.

There is some evidence that this strategy is in fact used. Firstly, that subjects mark "trouble figures", independent of their names appears, on the one hand, from the fact that the order of mention effect is the same for all syntactic frames. Order of mention is not more affected if the two names are closely together in the same NP; the subject moreover tends to select the trouble figure's movement for his event description in the third and fourth frame. That indicates, that the figure is focussed upon in an early stage of speech planning, before the lexical decision is made. On the other hand, there is evidence that trouble figures tend to appear in first position even in case they have no allonyms. More precisely, if a figure that has been an experimental figure with allonyms in an earlier block of trials has its "normal" name in a succeeding block of trials, it still tends to be mentioned in first position. For the blocks in which no allonyms are assigned, i.e. where both figure names are "normal", we find that in a significant ( $p<.05$, t-test) $55.7 \%$ of the trials that figure is mentioned first which is a "trouble figure" in other blocks. The attentional set of focus on particular figures seems to extend somewhat over blocks of trials. Secondly, the second part of the strategy cannot work for these latter cases. Naming the trouble figure first cannot be done by releasing the allonym from STM, since there is no allonym in these cases. We would therefore not expect shorter speech latency if the trouble figure is mentioned in sentence initial position. We found this to be the case; the mean latency was even slightly longer (1116 vs. $1094 \mathrm{~ms}$ ).

The most likely, but surely post-hoc, explanation for the findings in this 
experiment is that the instructions induce the subject to focus perceptually on the experimental figure. It should be noticed that such a strategy was excluded in Lindsley's case, since Lindsley simultaneously introduced allonyms for all the objects in his pictures. Perceptually focussing just one or two particular objects would not have been a helpful strategy for his subjects. Since focussing is, clearly, a non-linguistic determinant of order of mention our experimental procedure is, in retrospect, unfit to test possible effects of lexicalization difficulty on order of mention.

How else could we affect lexical difficulty? It should be a procedure which cannot induce the subject to focus beforehand on a particular figure. Moreover, we would like to use "normal" names only and not focus subject's attention on a particular name, so that subjects would not be able to give precedence to one name by using special STM-strategies.

The next experiment makes use of already existing differences in figure naming difficulty. It is known that some words are harder to retrieve than others, and this may also be true for names of geometrical figures. If, for instance, "circle" is relatively easy to retrieve and "diamond" relatively hard, then we can ask if there is a preferred order of mention, i.e. "circle"-first, for particular syntactic frames. In such an experiment, the subject is fully unconscious of the experimental variable; there is no reason to expect focussing on particular figures, nor on particular figure names.

As we suggested earlier, the theory we would prefer is one where lexical search does not affect order of mention, i.e. where linearization and functional decisions have a hierarchical one-way rather than a heterarchical twoway relation. A hierarchical theory here predicts that lexical difficulty will not affect order of mention. But a negative result might only mean that the method of measurement is too insensitive. Two precautions were taken to preclude this type of interpretation. First, we used stimuli and syntactic frames which did give rise to order of mention effects in the previous experiment. Secondly, we measured speech latencies to ascertain that variation in lexical difficulty was still affecting the sentence production process.

\section{EXPERIMENT 2. USING NORMAL NAMES: HARD AND EASY ONES}

This experiment consisted of two parts. The preliminary part was to determine naming latencies for different geometrical figures, in order to objectively choose relatively "hard" and "easy" names. This preliminary experiment in turn consisted of two parts. It is important to ascertain that differences in naming latency are not due to differences in perceptual recognizability of 
figures, but only to naming a figure once recognized. So, apart from measurements of naming latency, the preliminary experiment included measurements of recognition latencies. Figures which differed in naming latency but were equal in recognition latency were then used in the main experiment. There, we again determined order of mention and speech latency for two-event descriptions.

\section{Preliminary Experiment}

\section{Method}

Ten different figures were used: square, diamond, pentagon, cross, rectangle, triangle, star, ellipse, circle, and sickle or (half) moon. These were presented one-by-one in blocks of 60 trials. The time course of one trial was as follows: first, a small cross appeared in the middle of the visual display, accompanied one second later by a figure which appeared above it and the subject reacted as quickly as possible. The figure remained present for one second, then the picture disappeared. Again, the experiment was self-paced; the subject initiated the next trial by pushing a button. The order of trials within blocks was fully randomized with the restriction that no figure could occur more than two times in succession.

In the naming part of the preliminary experiment subjects had to name the figures shown as quickly as possible and the latency of this response, the time between appearance of the figure and onset of the description, was measured. When an error occurred, the picture was presented again at the end of the block. Before the naming blocks were presented, subjects received 30 practice trials; they rapidly and spontaneously used only the names mentioned in Table 1. Each subject received four naming blocks, naming each figure a total of 24 times.

The recognition task was done with the same subjects. The same blocks of pictures were presented (in a different order), but now, instead of naming the figures, subjects were asked to press a "yes"-button if the presented figure was the target-figure for that block (a figure specified as such by instruction) and a "no"-button if it was one of the other nine figures. To keep the situation comparable with the naming condition, the same blocks of trials were presented; thus, the ratio of number of "yes" to number of "no"-responses was 1 to 9. The "yes" and "no"-buttons were pressed with right and left index fingers respectively.

Every subject was given four recognition blocks with four different target 
figures. Each of the ten figures was target figure once in each of the four serial positions of recognition blocks (blocks that did not fit this design were left out in final analysis). Half of the subjects did the naming task first, and half the recognition task. Position by blocks within the recognition task was counterbalanced over figures.

The experimental setting was the same as in Experiment 1. There were 14 subjects, selected from the same pool as in the previous experiment, but with no overlap. A 15th subject was given 10 recognition blocks only, one for each figure.

\section{Results}

Distributions of percentages of errors, mean latencies and mean variances of latencies were determined in the same way as in Experiment 1. One subject was eliminated because of a computer breakdown during his session. Another was dropped for having an extremeley high mean variance and generally slow mean latency of responses in the naming task.

In Table 1 schematic drawings of the ten figures and their Dutch names are presented together with mean naming-latency $\left(\mathrm{RT}_{\text {nam }}\right)$, recognition latencies ( $\mathrm{RT}_{\text {yes }}$ - the mean latency of yes-responses) and the difference between these two $\left(\mathrm{RT}_{\mathrm{nam}}-\mathrm{RT}_{\text {yes }}\right)$. An analysis of variance was carried out on both naming latencies and recognition latencies. In the analysis of the naming latencies the factor Figures was significant $\left(\mathrm{F}_{9,99}=7.71, \mathrm{p}<.01\right)$. In the analysis of the recognition latencies, the factor Figures was not significant $(F<1)$, only the interaction between Serial Position and Figures $\left(\mathrm{F}_{36,247}=3.85, \mathrm{p}>.001\right)$. So, unlike naming-latencies, recognition latencies are not significantly different for the ten figures.

We took the differences between the naming latencies and the recognition latencies, shown in the last column of Table 1, to reflect the time needed for retrieving the figure names. By inspection of these differences, two sets of three figures each, were selected, a difficult set, whose names were relatively hard to retrieve (square, diamond and pentagon) and a set of figures with easily retrieved names (triangle, circle and moon). The difficult figures had a mean naming latency of $769 \mathrm{~ms}$ and a mean recognition latency of 511 $\mathrm{ms}$. For the easy figures these values were $686 \mathrm{~ms}$ and $506 \mathrm{~ms}$ respectively. In an analysis of variance on naming-latencies of these six figures, with easy and difficult groups introduced as a "lexicalization factor", the difference between these groups was significant $\left(\mathrm{F}^{\prime}{ }_{1,7}=19.00, \mathrm{p}<.01\right)$; Figures within groups was not significant $\left(\mathrm{F}_{4,44}=2.35, \mathrm{p}>.05\right)$. In the same analysis on 


\begin{tabular}{|c|c|c|c|c|}
\hline FIGURE & DUTCH NAME & $R T_{\text {nam }}$ & ${ }^{R T} T_{\text {yes }}$ & $R T_{\text {nam }}-R T_{\text {yes }}$ \\
\hline & "vijfhoek" & 765 & 499 & 266 \\
\hline & "vierkant" & 772 & 510 & 262 \\
\hline & "ruit" & 770 & 524 & 246 \\
\hline & "ster" & 707 & 473 & 234 \\
\hline & "kruis" & 732 & 499 & 233 \\
\hline & "rechthoek" & 730 & 497 & 233 \\
\hline & "ellips" & 703 & 478 & 225 \\
\hline & "driehoek" & 710 & 526 & 184 \\
\hline & "maan" & 656 & 477 & 179 \\
\hline & "cirkel" & 691 & 516 & 175 \\
\hline
\end{tabular}

TABLE I.

The presented figures and their Dutch names of the preliminary part of Experiment 2, together with mean naming latency $\left(\mathrm{RT}_{\text {nam }}\right)$, recognition latency, i.e. mean latency of yes-responses ( $\left.\mathrm{RT}_{\mathrm{yes}}\right)$ and the difference between the two $\left(\mathrm{RT}_{\text {nam }}-\mathrm{RT}_{\text {yes }}\right)$, all in $\mathrm{ms}$. The underlined figures are those selected for further experimentation.

recognition latencies neither effect has significance ( $\mathrm{F}<1$ for each).

From these data it was now possible to construct the main experiment. As a main experimental variable, it contrasted the three figures with "easy" 
names (triangle, circle and moon) with the three with "hard" ones (square, diamond and pentagon).

\section{Main Experiment}

\section{Method}

The pictures presented on any trial consisted of three figures, positioned in triangular form around a small cross used as a fixation point. In most cases two of the three figures made a phi-movement in upward or downward direction. The time course of one presentation was the same as in Experiment 1.

The experiment again was divided into blocks of trials. Each block consisted of 30 trials: 3 practice trials, 18 experimental trials and 9 distraction trials. In the experimental trials two figures moved, both upwards or both downwards, one chosen from the easy set (triangle, circle and moon) and one from the difficult set (square, diamond and pentagon). The third figure, which remained motionless, was chosen randomly from the six figures, but was as often a difficult figure as an easy one. The six possible position combinations in the pattern for the easy and difficult moving figures were used equally often. Of the distraction trials, in three cases no figure moved; the subjects were here to say either nothing or "nothing". In the remaining six distraction trials only a single figure moved, one trial for each; these diaplays were to be described with the frame " $x$ gaat omhoog/omlaag" (" $x$ goes up/down").

Since latency differences as a function of lexical difficulty were not found in Experiment 1 for construction (4), it was omitted here. Only syntactic frames (1) NPC (" $x$ and $y$ gaan omhoog/omlaag"), (2) SC (" $x$ gaat omhoog/ omlaag en $y$ gaat omhoog/omlaag") and (3) SS (" $x$, die naast/boven/onder $y$ staat, gaat omhoog/omlaag") were used. Syntactic frames were varied between blocks, with each subject receiving each frame type in two blocks, in a counterbalanced order (ABCCBA). The order in the first $\mathrm{ABC}$ run, and thus also in the CBA run, was varied according to a Latin Square design.

The experimental setting and task were the same as in Experiment 1 for both the subjects and the experimenter. There were 21 fresh subjects from the same pool as in the preceding experiments.

\section{Results}

Three subjects had mean latencies and mean latency variances that were both at least two standard deviations from the group means of the remaining 
subjects. Two of these three also had an unusually high percentage of errors ( $23 \%$ vs. $10 \%$ for the remaining subjects). And one subject had a mean latency $(1710 \mathrm{~ms})$ almost twice the overall mean. These four subjects were all excluded from further analysis performed on the remaining seventeen.

All descriptions of two moving figures contained an easy and a difficult figure name. Contrary to Experiment 1, there was no significant tendency for either of them to appear more often in sentence-initial position: in 51\% of the cases the easy name came first and in $49 \%$ the difficult name. As in Experiment 1, there was again no effect of syntactic frames on order of mention. In an analysis of variance on the transformed proportions of utterances that started with an easy name, with as main factors Subjects, Version (first vs. second run through the syntactic frames), Syntactic Frames and Figure Pairs, only Figure Pairs $\left(\mathrm{F}_{8,128}=2.227, \mathrm{p}=.029\right)$ and Version $\left(\mathrm{F}_{1,24}^{\prime}=\right.$ $7.374, \mathrm{p}=.011)$ were significant. Syntactic Frames was not significant $(\mathrm{F}<$ 1). The proportion of utterances starting with an easy name was $52.8 \%$ for frame NPC, $49.2 \%$ for frame SC and $51 \%$ for frame SS. With respect to figure pairs there was a slight tendency to start with the circle and a bit stronger tendency to start with the pentagon. With respect to Version, there was a non-significant tendency to start with the easy figure (in 53\% of the cases) in the first three blocks and with the hard figures in the last three blocks $(51.9 \%)$.

Thus, the variation in naming difficulty had little effect on order of mention. It did, however, affect the latency to speech.

The upper curve of Figure 3 plots the mean latencies of utterances describing two moving figures and starting with the name for the figure depicted on the $x$-axis. In an analysis of variance of these latencies, Naming Difficulty (that is ED vs. DE utterances) had a highly significant effect $\left(\mathrm{F}_{1,16}=84.279\right.$, $\mathrm{p}<.001)$ as did Syntactic Frames $\left(\mathrm{F}_{2,32}=34.426, \mathrm{p}<.001\right)$. When figures within groups is added as a random factor in the analysis, Naming Difficulty still is significant $\left(\mathrm{F}^{\prime}{ }_{1,5}=12.954, \mathrm{p}=.016\right)$ as is Syntactic Frames $\left(\mathrm{F}_{2,19}=\right.$ $16.792, \mathrm{p}<.001)$. Figures within groups is itself significant $\left(\mathrm{F}_{4,64}=4.062\right.$, $\mathrm{p}<.01)$. Clearly, two-event utterances starting with an easy name are initiated faster than those starting with a difficult name. The same holds for utterances describing only one moving figure, which can be taken as an independent measure of meaning latencies for the figures in these sentence contexts. The middle curve of Figure 3 plots these latencies. Analysis of variance was performed on them as with the double name utterances. Again significant were: Naming Difficulty $\left(\mathrm{F}_{1,16}=38.435, \mathrm{p}<.001\right)$ and Syntactic Frames $\left(\mathrm{F}_{2,32}=15.736, \mathrm{p}<.001\right)$. Again, when Figures within groups is added as 


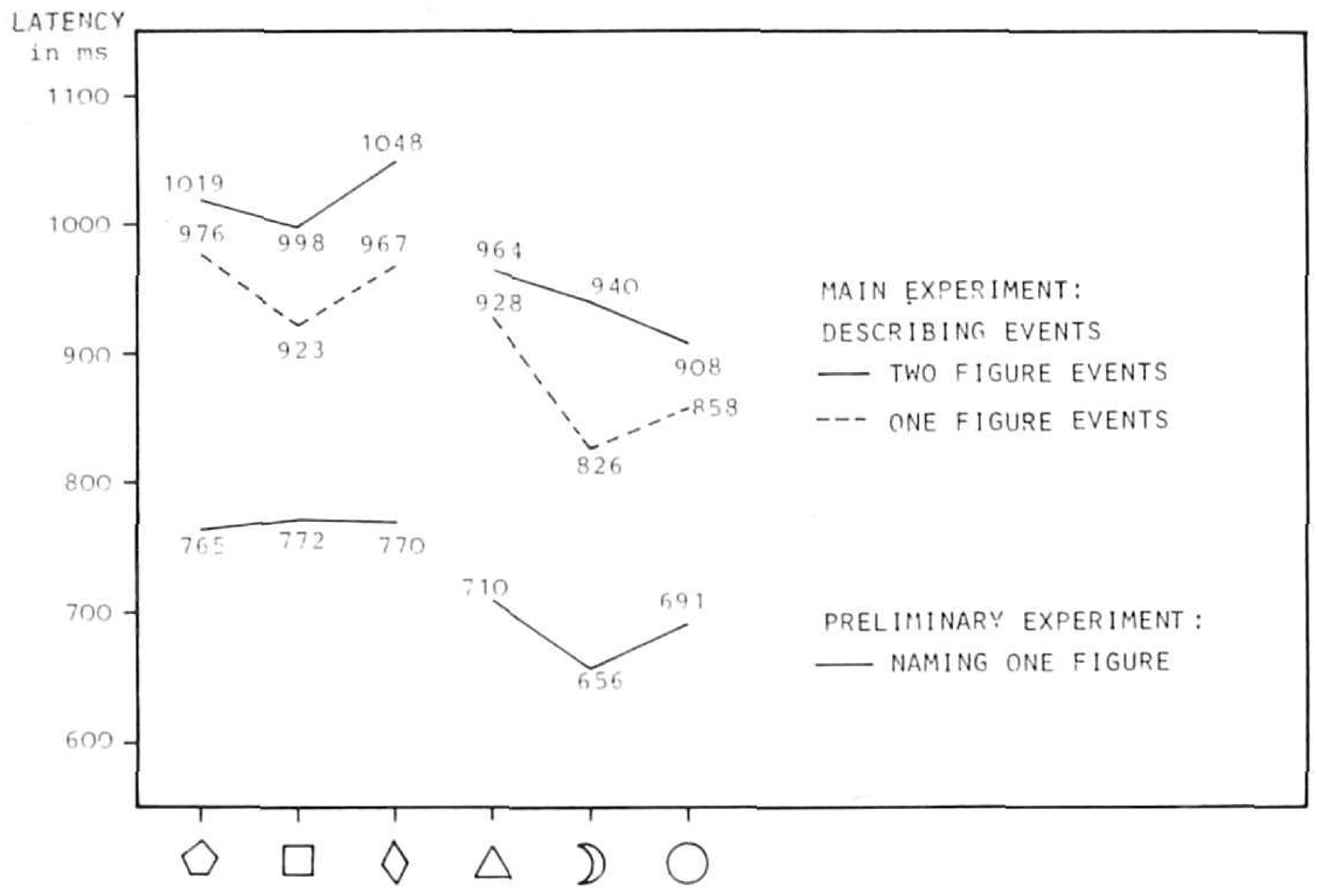

Fig. 3. Mean latencies of Experiment 2. The lower curve represents the naming latencies of the preliminary experiment, the middle and upper curve the latencies of utterances for description of one- and two-figure events. On the abscissa are the figures named in initial position (for the one-event descriptions these are, of course, the only figures mentioned)

random factor, Naming Difficulty nearly reaches significance $\left(\mathrm{F}^{\prime}{ }_{1,5}=5.353\right.$, $\mathrm{p}=.067)$. Syntactic Frames remains significant $\left(\mathrm{F}_{2,27}^{\prime}=8.492, \mathrm{p}<.01\right)$, and Figures within groups $\left(\mathrm{F}_{4,64}=8.128, \mathrm{p}<.01\right)$ and the interaction between Syntactic Frames and Figures within groups $\left(\mathrm{F}_{8.128}=2.432, \mathrm{p}=\right.$ .017) are significant. For comparison the naming latencies of the preliminary experiment are also depicted in the bottom curve of Figure 3.

As in Experiment 1 there were consistent latency differences between syntactic frames; utterances of the form SS took longest to initiate, followed by NPC and SC (see the upper curve in Figure 4). Even the smallest difference, between NPC and SC, is reliable $(t=2.687, \mathrm{df}=32, \mathrm{p}<.01$ one-tailed $)$.

A rather queer result is represented in the lower curve of Figure 4. For the utterances describing one moving figure, the differences between syntactic frames are exactly the same as for the two figure descriptions. But here it is not the frame of the utterance itself which is meant (this was " $x$ goes up/ down" throughout the whole experiment), but the syntactic frame of the other utterances of the block in which it is embedded; this is a significant effect $(\mathrm{p}<.01)$, to which we will return in the discussion. 


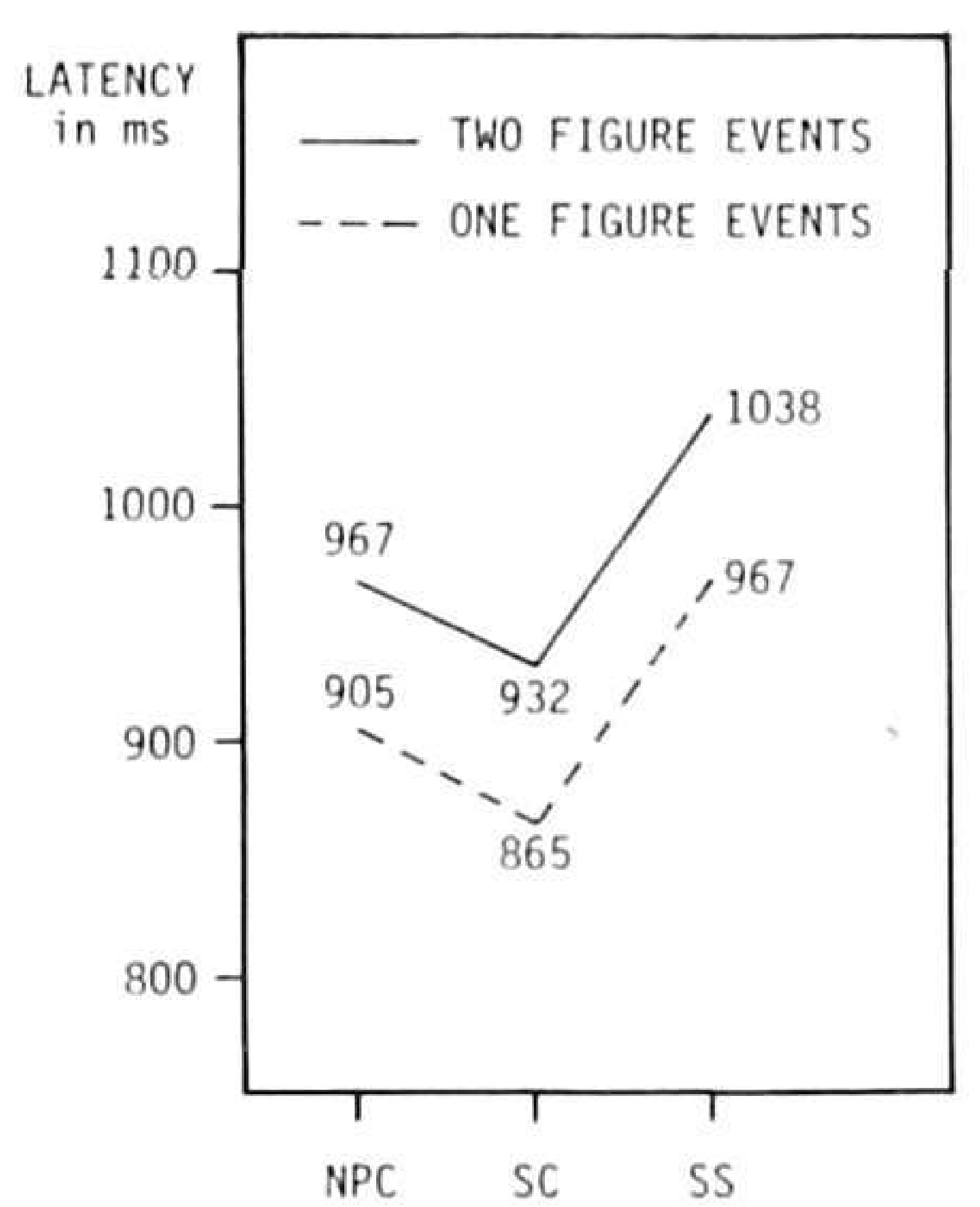

Fig. 4. Mean latencies of Experiment 2, for syntactic frames NPC, SC and SS. The upper curve represents the utterances containing two figure names. The lower curve gives latencies for the single-name utterances which appear in the blocks defined by the two-event syntactic frames NPC, SC and SS.

\section{Discussion of the results}

Before discussing the main findings on order of mention it should be noticed that difficulty of naming was indeed an effective variable in the experiment qua latency to speech. For each of the three syntactic frames, speech latency was longer if a difficult name appeared in sentence-initial position. It was on the average $85 \mathrm{~ms}$ longer, which is nearly the same as the average $83 \mathrm{~ms}$ difference in naming latency found between difficult and easy figures in the preliminary experiment.

It is therefore a remarkable result that no effect was found for order of mention. The easy name appeared in first position in a non-significant $51 \%$ of the trials, and there were no significant differences between the three syntactic frames in this respect. From this, the conclusion can be drawn that the speaker decides on the order of mention irrespective of difficulty of lexical search. There is, moreover, inferential evidence that the order of mention decision is taken before lexical search occurs. If it took place after lexical retrieval one would not expect an effect on speech latency itself since both names would be available before the start of speech. The process, therefore, seems to be that after perceiving the events, the speaker decides on an order of mention, and only then retrieves the figure names: If the first figure 
to be mentioned happens to have a hard-to-retrieve name, the speech process will be retarded; if it has an easy name the process will be speeded up.

The latencies measured show another interesting variation as well: the three syntactic frames differed significantly in voicing latency. As can be seen from Figure 4, latencies were shortest for the sentence-coordinated frame (" $x$ goes up/down and $y$ goes up/down"), longer for NP-coordination (" $x$ and $y$ go up/down") and longest for the subordinated construction (" $x$, which is next to $y$, goes up/down"). This conforms to the pattern of results in Experiment 1 . It would, however, be premature to assign much value to these differences. If a speaker found a particular frame more appropriate for describing what he saw, the mean latency for this frame could be expected to be relatively short, and inversely for inappropriate frames. Intuitively, the subordinated construction used here seems quite inappropriate for any of the events to be described, which may explain the greater delay in articulatory latency. This could be called a "congruency"-effect for speaking, and may have nothing to do with the "intrinsic" difficulty of a particular syntactic frame. Neither the present experiment nor the previous one, however, can distinguish between appropriateness and intrinsic difficulty, since by instruction the subjects were not given freedom of choice. Only if the syntactic frame is unrestricted can one assume that a speaker gives an appropriate formulation. Then, any remaining differences in latencies between frames should have to do with "intrinsic" formulation difficulties for different frames. This argues for an experiment in which there is freedom of formulation.

There is a related argument for trying to replicate the present findings under free choice of sentence constructions. Normally, a speaker would generate a syntactic form at the occasion of each event to be described, but here, with blocked presentation, speakers were essentially asked to store the experimental frame in memory and use it for each two-event trial. It is immaterial for the present argument whether this use is a retrieval of the frame for constructing the utterance, or whether the stored frame is to be used as a criterion by the speaker while monitoring his own production (as proposed by Kempen and Huybers, 1980). The evidence we have that the subject has a special attentional set for the block's syntactic frame is that the latencies for single-event descriptions also differed between blocks (cf. Figure 4). If a block had a difficult two-event frame (such as the subordinate construction), latencies were generally relatively long, not only those in which that frame itself had to be used (the two-event cases), but also those where the frame was not used (the single-event cases in a block). As was noted above, these differences between blocks on single-event descriptions 
were also reliable. Thus, we might suppose that, dependent on the frame, short-term memory load varied from block to block, and affected the latencies for all descriptions in a block. The latency differences found between syntactic frames therefore, can be due to the short term memory load they create, rather than to any "intrinsic" difficulty in generating those frames.

\section{EXPERIMENT 3. FREE FORMULATION}

In this experiment, possible effects of lexicalization difficulty on order of mention were studied under conditions of free formulation. We decided to slightly increase the range of events to be described in order to reduce the likelihood that subjects would themselves generate a "stock frame" and hold it in short term memory throughout the experiment. To the set of two-event stimuli, we added, firstly; the possibility that the one figure would go up and the other go down; this would presumably make sentence-coordination ( $x$ goes up and $y$ goes down) more appropriate than forms of NP-coordination. Secondly, we added as "filler'-trials cases where the two moving figures were of identical shape. This would lead (and in fact led) to a variety of other syntactic constructions (such as "two diamonds go up").

Another change in the experiment was made to elaborate our earlier findings indicating that speech latencies are shorter if a description has begun with an easy name. The design of the previous experiment made it impossible to check independently whether lexicalization difficulty has a general effect on speech latency. There were always one easy and one difficult name involved in a trial. We thus wanted to learn whether latencies would be shorter if both names were easy than if only the first one mentioned was (and similarly whether latencies would be longer if both names were difficult rather than just the first one). For this reason, events were added where both moving figures had easy names, or both had difficult names. In more detail, the experimental design was as follows.

\section{Method}

The pictures presented again consisted of three figures positioned in triangular form around a small cross used for fixation, as in Figure 1. In every presentation one or two figures moved. Catch-trials with no moving figures were left out. The time course of a single presentation was the same as in the earlier experiments.

The pictures were presented in blocks of $60: 6$ practice trials, 12 trials in 
which one figure moved, 6 trials in which two identical figures moved and 36 trials in which two different figures moved. Of these latter trials, there were 18 where one easy and one difficult figure moved, that is one figure was chosen from the set triangle, circle and moon and the other from the set pentagon, square and diamond. These items we will call ED or DE, depending on the order used in a subject's description. This replicates the conditions of Experiment 2. In addition, there were 9 trials in which two easy figures moved (condition EE) and 9 where two difficult figures moved (condition DD). The cases with only a single moving figure (condition S) offered an opportunity to compare lexicalization in a sentential context to the pure naming data of Experiment 2; each of the six figures moved alone twice in each block. There are six position-combinations for two different moving figures and three for two identical moving figures. Within a block all position combinations were equally often used as far as "easy" versus "difficult" figures were concerned. For combinations of particular figures a complete balancing over figures was realized over blocks, so that in the end every pair of figures occured in all position combinations equally often. This also holds for direction of movement. In half the trials the two figures moved in opposite directions (one up and one down), in the other half they moved in the same direction (both up or both down). This was also varied within blocks as much as possible in every relevant condition. Each subject received three blocks of trials preceded by about 20 or 30 practice trials.

On each trial, subjects were free to choose the syntactic frame of the description given. In practice, however, they almost exclusively used the frames NPC and SC. In order to code this distinction, the experimenter used a second set of code buttons, apart from those used to indicate with which figure name the utterance started, to indicate syntactic frames (NPC, SC and "other"). The computer program was designed to wait for both button presses and after some practice the experimenter could perform this without noticeable delay for the subjects being tested. Apart from the voice onset latencies, the voice offset latencies were also measured. This made it possible to determine utterance durations.

The setting for the experiment was the same as earlier. There were 23 subjects, again paid volunteers from the same pool, all attending this type of experiment for the first time.

\section{Results}

In the same way as in preceding experiments, distributions of mean latencies, 
mean latency variances and mean percentage of errors were calculated. One subject had a high percentage of errors ( $24 \%$ vs. $8 \%$ for subjects not excluded). Three subjects had extremely high latency variances, and one of these three also had an extremely high mean latency. These four were excluded from further analysis, which was thus performed on the remaining 19 subjects.

The main question, whether naming difficulty influences order of mention again has to be answered negatively. Of the utterances containing one easy and one difficult name $52.5 \%$ started with the easy and $47.5 \%$ with the difficult name. This difference is not significant $(\mathrm{t}=1.611, \mathrm{df}=18, \mathrm{p}>.10$ two-tailed).

Subjects themselves could choose the syntactic form of their utterances. The frames NPC (" $x$ and $y$ go up/down") and SC (" $x$ goes up/down and $y$ goes up/down") were chosen almost exclusively. Frame SC was used more frequently (in $61.2 \%$ of the cases) than frame NPC (38.8\%); this difference is clearly significant $(t=5.907, d f=18, p<.001$ two-tailed $)$.

As in the previous experiments, there was no interaction between syntactic frame and order of mention. In an analysis of variance on the (transformed) proportion of utterances containing an easy and a difficult name which started with the easy one, i.e. ED-sentences, only the factor Figure Pairs $\left(\mathrm{F}_{8,144}=\right.$ $3: 203, \mathrm{p}<.01)$ and the interaction between Syntactic Frames and Figure Pairs $\left(\mathrm{F}_{8,144}=2.263, \mathrm{p}=.025\right)$ were significant; Syntactic Frames by itself had no effect $\left(\mathrm{F}^{\prime}<1\right)$. The significant findings for Figure Pairs and its interaction with Syntactic Frames was due to a tendency to start a description with a moving circle shown, especially in the cases where syntactic frame NPC was chosen. This preference totally accounts for the slight difference between percentages of ED and DE utterances.

As to the second main question, the effect of naming difficulty on onset latency, mean latencies of utterances starting with each of the figures are presented in Figure 5. Utterances beginning with an easy name were initiated significantly faster than utterances starting with a difficult name; the difficulty of the second name spoken in the sentence has no influence (mean latencies of EE versus ED utterances are 998 and 991 ms respectively; for DE and DD utterances these values are 1030 and $1032 \mathrm{~ms}$ ). In an analysis of variance on the latencies, with as fixed factors Syntactic Frames, Difficulty of First Name (that is, EE and ED vs. DE and DD utterances) and Difficulty of Second Name (EE and DE vs. ED and DD), only difficulty of First Name $\left(\mathrm{F}_{1,18}=11.357, \mathrm{p}<.01\right)$, and Syntactic Frames $\left(\mathrm{F}_{1,18}=13.101, \mathrm{p}<.01\right)$ were significant. Thus, the difference between easy to name and difficult to name figures was again validated. 


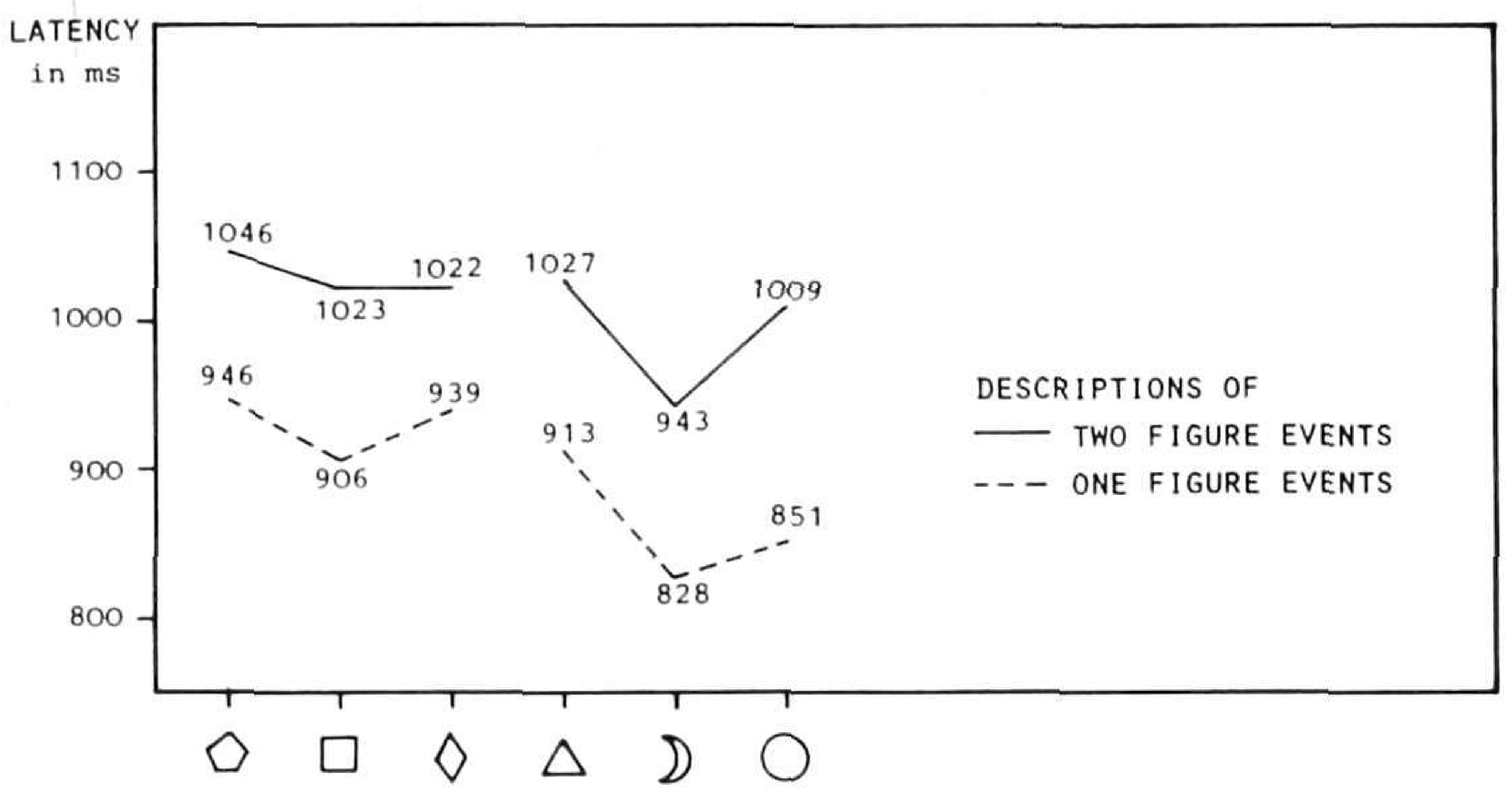

Fig. 5. Mean latencies of the utterances in Experiment 3 with the figure on the abscissa mentioned in initial position. Upper curve (drawn line) is for two-figure events, lower curve (dotted line), is for one-figure events.

The lower curve in Figure 5 shows onset latencies of utterances describing single moving figures. In an analysis of variance on these utterances, Naming Difficulty $\left(\mathrm{F}_{1,18}=27.281, \mathrm{p}<.001\right)$ was also significant. When Figures within groups is added as a random factor, the result remains $\left(\mathrm{F}^{\prime}{ }_{1,6}=4.971, \mathrm{p}=\right.$ $.066)$, and Figures within groups $\left(\mathrm{F}_{4,72}=2.877, \mathrm{p}=.028\right)$, is also significant.

\section{Discussion of the results}

As in the previous experiment lexicalization difficulty was an effective influence on speech onset latencies: if an easy term appeared in first position speech latency was shorter than if a difficult term appeared first. An additional result was that the ease or difficulty of the second name had no effect on this latency. This suggests that the second name used was not retrieved before the start of speech. We will return to this finding later in the discussion.

Though lexicalization difficulty had a measurable effect on task performance, it did not affect order of mention. The easy term appeared in first position in only $52.5 \%$ of the sentences produced. This confirms the findings of the previous experiment, now under conditions of free formulation. The main conclusion from the present experiments, therefore, must be that order of mention is not affected by lexical search. In other words, there is a process hierarchy in the production of speech in which there is no feedback from lexicalization processes to linearization decisions. The present results are not 
sufficient to make the much stronger claim that order of mention decisions have only feed-forward but no feedback relations to the level of linguistic decisions, i.e. functional and positional decisions in Garrett's model. Still, they are in full agreement with such a state of affairs.

Some of the results in the present experiment may also throw light on other relations between components of the speech production mechanism. The first of these concerns some possible other determinants of linearization. One factor that clearly affects linearization is the spatial arrangement of the two moving figures. There are three possible orientations between them, given the triangular stimulus arrangement (see Figure 1). When the two figures at the base of the triangle moved, then in $55.2 \%$ of the cases they were described in the order left-first, right-second. When the top figure moved together with one of the bottom figures, they were described from top to bottom $74.9 \%$ of the time when the other figure was on the bottom left, and $78.5 \%$ of the time when it was the bottom right figure. So, clearly, there is both a weak tendency to describe from left to right and a strong one to describe from top to bottom. In the description of cases in which one figure moved up and the other one down, subjects had no systematic preference for first mentioning either motion.

A second result concerns the choice of syntactic frames. In the free choice situation, subjects almost exclusively (in more than $99 \%$ of the cases) used the NP-coordinated or S-coordinated sentence frame. NP-coordination, however, was less frequent (38.8\%) than S-coordination (61.2\%). One obvious determinant of this difference is the type of event presented. Descriptions of "disjunctive" events, where the figures move in opposite directions, always take the sentence-coordination form: " $x$ gaat omhoog en $y$ gaat omlaag" (" $x$ goes up and $y$ goes down"). Clearly NP-coordination in these cases (such as " $x$ and $y$ move") was not felt as a convenient description type. For cases where the two movements were in the same direction, on the other hand, S-coordination was used in only $22 \%$ of the cases. It is thus clear that Scoordination was preferred for describing "disjunctive" movements and NP. coordination for "conjunctive" movements. One could summarize this by saying that there is a "congruency principle" which gives optimal linguistic expression to a perceptual configuration. Others have obtained similar results under quite different experimental conditions (see e.g. Flores d'Arcais, 1975).

A third set of results relates further to this, but concerns relations only within the level of formulation. Though NP-coordination is the preferred frame for describing conjunctive movement, we found that latencies for 
NP-coordination are systematically $(\mathrm{p}<.01)$ longer than for S-coordination. Figure 6 shows the latencies for the NP- and S-coordinated frames for conjunctive movements (both up or both down), plus the latencies for the Scoordination for disjunctive movements (one up and one down - there being no cases of NP-coordination in this latter case).

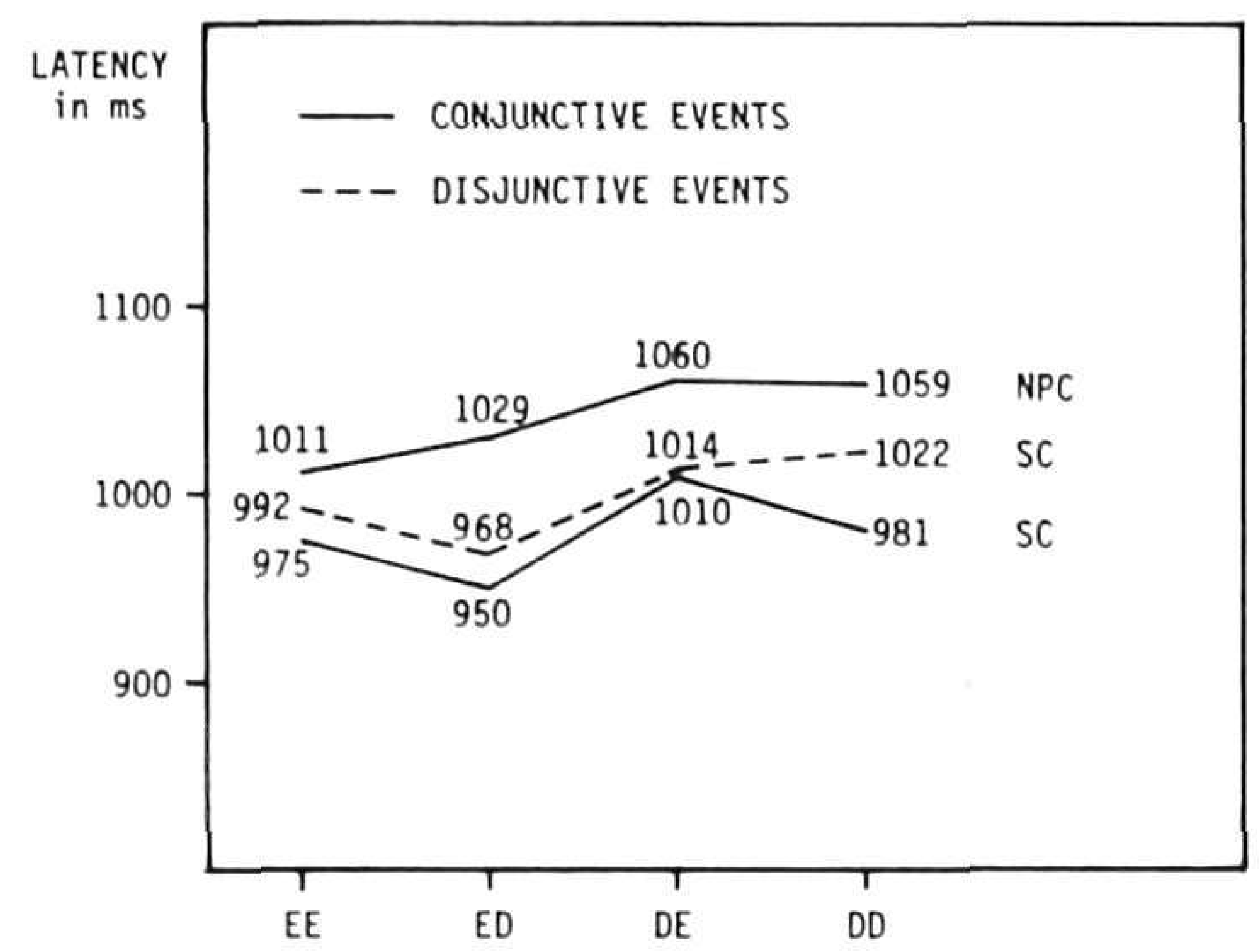

Fig. 6. Mean latencies of Experiment 3. The upper and lower (drawn) curves represent the latencies for descriptions of "conjunctive" events (both figures go up or both down). The upper curve is for descriptions containing noun-phrase coordination; the lower curve for sentence-coordinated descriptions. The middle (dotted) line gives latencies for descriptions of "disjunctive" events (one figure up, the other down); these were all sentence-coordinated. The abscissa partitions the latencies according to the order of "easy" and "difficult" names in the utterance.

The figure shows clearly that in general the latencies for easy-name-first utterances are relatively short. But it is clear that NP-coordination takes more time to initiate than S-coordination, even when both can be considered as appropriate syntactic frames (i.e. for conjunctive and disjunctive movements, respectively). The latencies of S-coordinated descriptions for conjunctive and disjunctive events, on the other hand, are not reliably different (the bottom two curves in the figure).

Why does it take longer to initiate an NP-coordinated frame? This cannot be due to a strategy whereby a speaker initiates speech for NP-coordinates only after both figure names have been retrieved. As was noted earlier, that strategy would predict that the difficulty of the second name mentioned should also affect speech latencies. But as the figure shows, it doesn't: for NP-coordination there is only a small, non-significant difference between EE 
and ED frames, and no difference between DE and DD frames. So, that strategy cannot have operated. A slightly modified version of this hypothesis could be stated with reference to the Kempen and Hoenkamp (1979) model of speech production. These authors distinguish between retrieval of a lemma and retrieval of the phonetic form of a lexical item. The lemma contains semantic and syntactic properties of a lexeme, but not its sound or articulatory structure. The latter may be retrieved at a later stage, for instance after "positional level" decisions have been taken (See also Garrett, 1980, for a discussion of this "double retrieval" hypothesis).

The lexicalization difficulty in our experiments can be interpreted in this model as a difficulty of retrieving the articulatory form of the item, given the lemma. The subject's strategy for NP-coordination would thus be to, first, decide on NP-coordination and to retrieve both lemma's, second, to retrieve the phonetic form of the first name and to initiate speech, and third, i.e. during speech, to retrieve the articulatory form of the second name. In this way the latencies of Figure 6 could be explained, since only for NPcoordination would both lemmas be retrieved before sentence initiation. For S-coordination, only one lemma would be retrieved beforehand. Then, for both frames just the first lemma would be given articulatory shape before the initiation of speech. If retrieving the phonetic form is easy, latency would be relatively short. For both frames retrieving the other phonetic form would occur during speech and therefore not affect speech latency.

This model cannot be completely correct either, however. We were able to make the following important additional observation: DD-cases (where both names given were difficult) tend to give significantly more S-coordinations than EE-cases (68\% and 61\%, respectively, $\mathrm{p}<.05$ ), and then ED or DE cases (60\% and $62 \%$, respectively). There are two ways by which this result might have been obtained. First, the decision between the two syntactic frames might have been taken only after the initiation of speech, however, this would result in no latency difference between NP- and S-coordinated constructions, and that is not what we find. Second, the frame-decision might be taken before initiation of speech, as was assumed in the above-model, but with the speaker taking into account some estimation of the difficulty of retrieving the articulatory forms of the elements needed; this must be only an estimation of retrieval, not retrieval itself, since, as we have seen, the articulatory form of the second element is apparently retrieved only after the initiation of speech. With this explanation, however, we also run into serious trouble. When it is possible to make an estimation of the retrieval effort for both articulatory forms, then at least both lemmas must be known 
to the speaker, since what else should he base his estimation on? But if both lemma's are available before the initiation of speech whatever the eventual choice of syntactic frame, we can no longer explain why S-coordinated constructions have systematically shorter latencies than NP-coordinated descriptions.

We propose the following solution. On the one hand, we assume that speakers normally decide on the syntactic frame rather early in the production process (and based on considerations of appropriateness, i.e. NP-coordinated frame for "conjunctive" events and S-coordinated frame for "disjunctive" events). Depending on the frame selected, the speaker then retrieves one or two lemmas before the initiation of speech, one lemma in case of S-coordination, two lemmas in case of NP-coordination. So far, this conforms fully to the model presented above. On the other hand, we make the additional assumption that it is possible for the speaker to revise the frame decision at a later stage. In particular, the speaker may switch from an initial NPcoordinated frame to an S-coordinated frame. This is especially relevant for cases where the retrieval of the articulatory form of the second noun is not completed in time to permit a fluent continuation of speech. The speaker may then decide to articulate the verb, which may have become available in the meantime. Thus, all findings can be explained by assuming a dual relation between syntactic and lexical decisions: each may precede or follow the other. Thus, for the case of conjoint movement and two "easy" names (but also for DE and ED), a subject would go through the following steps (leaving out steps that are irrelevant for the present discussion):

(1) On grounds of appropriateness, select an NP-coordinated frame

(2) Retrieve both lemmas

(3) Retrieve the articulatory form of the first lemma

(4) Initiate speech

(5) While speaking, retrieve the articulatory form of the second lemma

(6) Articulate second noun and formulate VP.

For the case of two difficult names, this procedure would sometimes be hindered by long retrieval times for the second articulatory form, and a different syntactic frame would be adopted to prevent or limit disfluency:

(1)-(5) as above

(6) If no timely result, revise frame and formulate first VP.

(7) Complete retrieval of the articulatory form of the second lemma

(8) Formulate second VP 
If, on grounds of appropriateness, an S-coordinated frame is chosen to start with, we assume that only one lemma and articulatory form is retrieved before initiation of speech, which explains the shorter latencies for these frames.

So, in the case of two difficult names, the total time for retrieving the two phonetic forms of the figure names would sometimes exceed the (parallel) retrieval of the verb's phonetic form. In that case a speaker may decide to shift frames from NP- to S-coordination. The mere difficulty of the second name is not, generally, enough for the speaker to decide on a frame shift: it should also be possible to shift, i.e., the verb should be available. This is more likely when both names are difficult than when only the second one is. If this explanation is correct, one would expect that this shift from NPto S-coordination during the utterance would lead to a lengthening of the utterance.

To investigate this in more detail, we decided to analyze the utterance durations, i.e. the time spans from speech onset to speech offset. Figure 7 pictures the duration for NP- and S-coordinated utterances, with the latter further partitioned by descriptions of "conjunctive" events (both figures moving in the same direction), and "disjunctive" events (moving in opposite direction). S-coordinated utterances are, not surprisingly, longer than NPcoordinated ones.

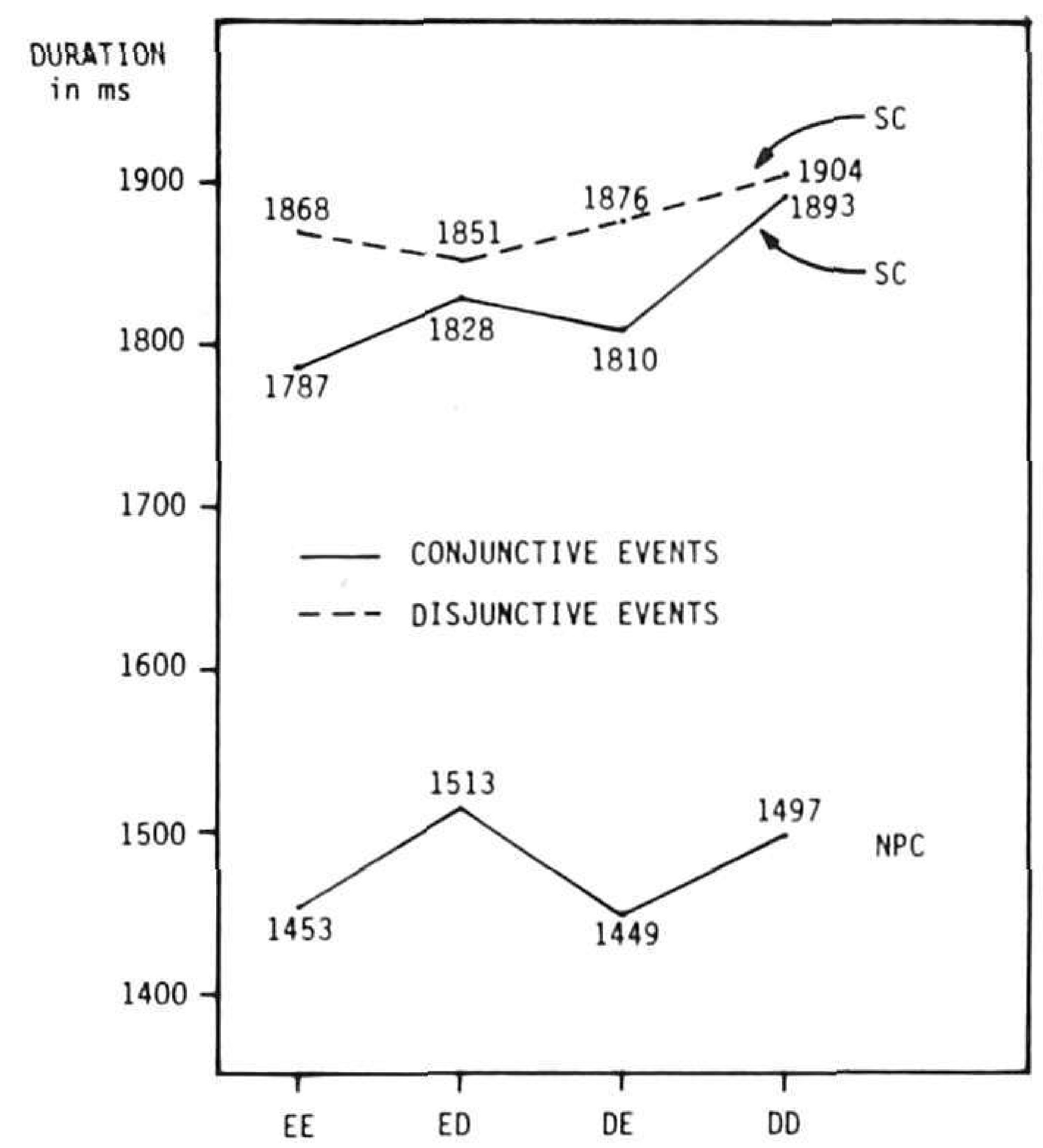

Fig. 7. Durations of utterances of Experiment 3. Drawn lines are for "conjunctive" events; the dotted line is for "disjunctive" events. 
Let us first consider the NP-coordinated descriptions (the bottom-curve in the figure). Clearly, utterance durations are longer for ED and DD than for the other two cases. $\left(F_{1,18}=20.138, p<.001\right)$. In other words, if the second figure noun is hard, the utterance becomes extended in time. So difficulty of the second figure name does have an effect on the subject's speech, but only on duration, not latency. This is just the reverse of the effect of the first figure name, which affected the latency as we have seen, but does not affect duration (see Figure 7).

What happens, then, if a conjunctive event is described with an S-coordinated utterance? We argued that, especially for cases where both figure names are difficult (DD-cases) such an S-coordinated frame may be the result of a frame shift, i.e. the speaker starting with an NP-coordinated frame in mind, and deciding while speaking to switch to an S-coordinated frame. This shift would require additional time. The middle curve of Figure 7 shows that this is indeed the case. The utterance length for DD-cases is much longer than for the other three cases (EE, ED, and DE - the significance level for the differences is, by t-test, $p<.01, p=.06$, and $p<.03$, respectively). If this is indeed due to frame shift, as we argue, then such a difference should not occur when the S-coordinated frame is operative from the very start. This is the case when a disjunctive event is described; here subjects choose $S$ coordination as the appropriate frame without exception. Durations for such sentences are seen in the topmost curve in Figure 7. Analysis of variance in this case shows no significant effect of first or second name difficulty; DDsentences do not take significantly more time even than EE ones. DD only differs significantly from ED ( $p<.025$, t-test), but this is of no relevance for the present argument.

In summary, it seems that, though speakers select an appropriate syntactic frame early in planning their utterance, they can change to another frame during speech itself. One cause for this can be "lexical trouble", an overtly time consuming process in retrieving a word's phonetic form. The actualization of a word, therefore, can affect how a sentence is generated. This is in agreement with the findings of Bock and Irwin (1980), who found that availability of a lexical item in memory could affect the syntactic frame in which it became used. In other words there seem to be heterarchical feedback and feed-forward relations between the functional and positional linguistic decisions in speech. But at the same time we found that lexical retrieval does not feed back to the level of order of mention decisions. Taken together, we have obtained evidence for a hierarchical organization in speech production, in which perceptual and order of mention decisions (i.e. decisions 
at the "conceptual level") precede and influence linguistic decisions, but where there is no return influence on the conceptual level. Lexicalization does not affect order of mention. It is hard for words to cross linguistic boundaries.

\section{Max-Planck-Institut für Psycholinguistik, Nijmegen}

\section{ACKNOWLEDGEMENT}

We are thankful to Robert Jarvella who has greatly contributed to the language and the logic of this chapter, and to Gerard Kempen who was a source of theoretical inspiration and helpful comments.

\section{REFERENCES}

Bierwisch, M.: 1979, 'Sprache und Gedächtnis: Ergebnisse und Probleme', in M. Bierwisch (ed.), Psychologische Effekte sprachlicher Strukturkomponenten, Berlin: AkademieVerlag.

Bock, J. K. and Irwin, D. E.: 1980, 'Syntactic effects of information availability in sentence production', Journal of Verbal Learning and Verbal Behavior 19, 467-484.

Bühler, K.: 1908, Tatsachen und Probleme zu einer Psychologie der Denkvorgänge', Archiv für die gesamte Psychologie 12, 1-92.

Bühler, K.: 1934, Sprachtheorie, Jena: Fischer (Stuttgart: Fischer, 1965 II).

Flores d'Arcais, G. B.: 1975, 'Some perceptual determinants of sentence construction', in G. B. Flores d'Arcais (ed.), Studies in Perception, Milano-Firenze: Martello-Giunti.

Garrett, M. F.: 1975, 'The analysis of sentence production', in G. H. Bower (ed.), The Psychology of Learning and Motivation, Vol. 9, New York: Academic Press.

Garrett, M. F.: 1980, 'Levels of processing in sentence production', in B. Butterworth (ed.), Language Production. Vol. 1: Speech and Talk, New York: Academic Press.

Kempen, G.: 1977, 'Conceptualizing and formulating in sentence production', in S. Rosenberg (ed.), Sentence Production: Developments in Research and Theory, Washington: Erlbaum.

Kempen, G. and Hoenkamp, E.: 1979, 'A procedural grammar for sentence production', Internal Report K. U. Nijmegen, Nov. 1979.

Kempen, G. and Huijbers, P.: 1980, 'The lexicalization process in sentence production and naming: indirect election of words', Internal Report K. U. Nijmegan, Oct. 1980.

Levelt, W. J. M.: 1979a, 'Linearization in discourse', memeo, Max-Planck-Institut für Psycholinguistik.

Levelt, W. J. M.: 1979b, 'Describing spatial networks'. To appear in Proceedings of the Sloan Symposium on Formal Semantics and Natural Language Processing. Held at Center for Cognitive Science, University of Texas.

Levelt, W. J. M.: 1981, 'Cognitive styles in the use of spatial direction terms', in R. J. Jarvella and W. Klein (eds.), Speech, Place and Action. Studies of Language in Context, Chichester: Wiley. 
Levelt, W. J. M. and Kelter, S.: 1981, 'Surface form and memory in question-answering', submitted to Cognitive Psychology.

Lindsley, J. R.: 1976, 'Producing simple utterances: Details of the planning process', Journal of Psycholinguistic Research 5, 331-354. 